\title{
Emprendedoras de la localidad de Chapinero innovan con un modelo de negocio social
}

Women entrepreneurs from the locality of Chapinero innovate with a social business model

\section{Camilo Antonio Castaño Martínez}

Investigador principal. Administrador de empresas. Magister en docencia, doctorando en administración de empresas, decano de la Facultad de Ciencias y Tecnologías, Universidad Santo Tomás, DUAD.

Correo electrónico: dec.cienciasytecnologias@ustadistancia.edu.co

\section{Blanca Rosa Restrepo de Peña}

Coinvestigadora. Economista, especialista en gestión para el desarrollo empresarial, magister en educación, doctoranda en educación. Docente del Programa de Administración de Empresas, Universidad de Santo Tomás, DUAD.

Correo electrónico: blanca.restrepo@ustadistancia.edu.co 


\section{Resumen}

Los resultados de la investigación se encaminan a identificar un modelo de negocio para orientar las ideas emprendedoras, nacientes y establecidas, hacia la creación de valor e innovación en un grupo de siete mujeres, dedicadas a desarrollar negocios de artesanías, bisutería y alimentos. A partir de la metodología de investigación acción aarticipativa, se benefició el grupo con un programa de capacitación y orientaciones de trabajo práctico, en diversos temas conducentes a mejorar las actividades del negocio individual. Con la identificación inicial, de intereses colectivos y necesidades de gestión de los emprendimientos, se realiza la caracterización del grupo de emprendedoras en la que se reconocen las dificultades de los negocios. Teniendo en cuenta la orientación de expertos, en paneles como fuente primaria, los análisis de las teorías, los modelos de negocios analizados por el equipo de investigación, se determinaron las principales variables para definir una propuesta de modelo de negocio, para los emprendimientos de la localidad de Chapinero.

Palabras clave: emprendimiento, innovación, modelo de negocio.

\section{Abstract}

The results of the research are aimed al identifying a business model to guide emerging and established entrepreneurial ideas towards the creation of value and innovation in a group of seven women, dedicated to developing jewel- ry and food crafts businesses. Based on the Participatory Action Research Methodology, the group benefited from a training program and practical work orientations on various topics conducive to improving the activities of the individual business. From the initial identification, of collective interests and management needs of the enterprises, the characterization of the group of women entrepreneurs is in which the difficulties of the enterprises are recognized. Taking into of the enterprises are recognized. Taking into account the guidance of experts, in panels as a primary source, the analysis of theories, business models by the research team, the main variables were determined to define a business model proposal, for local enterprises of Chapinero.

Keywords: entrepreneurship, Innovation, Business Model.

\section{Introducción}

La última monografía de la localidad de Chapinero presentada por la Alcaldía Mayor de Bogotá (2017, p.13) indica que esta localidad, "es uno de los sitios con mayor actividad comercial y de servicios en Bogotá, donde la concentración del sector bancario, de servicios educativos, de salud y empresarial es lo predominante", se encuentran diversos negocios con organizaciones pequeñas y medianas, a las que comúnmente se denominan pymes, hasta grandes empresas que invaden el mercado con sus productos y que algunas veces constituyen una multinacional, que cubre diversos puntos con las franquicias localizadas de manera diseminada en esta zona de Bogotá. El comercio informal en puntos estratégicos de la zona, ha 
generado el interés de entidades públicas y privadas para crear diversos programas de apoyo a los emprendimientos locales, especialmente en la población del sexo femenino, que cuenta con la Casa de la mujer, constituida y organizada por la Alcaldía Local, cuyo propósito, es el desarrollo de la educación con equidad, y cuyo postulado se enfoca a garantizar este derecho a las mujeres de manera pertinente, de calidad y libre de sexismo, que permita el desarrollo de sus capacidades y el ejercicio de sus derechos. Las actividades de las emprendedoras se apoyan con la Red de Mujeres de la Localidad de Chapinero, constituida por una líder comunitaria; las emprendedoras la utilizan para promocionar y difundir los trabajos manuales de artesanías, bisutería, tejidos, muñequería, productos en material reciclable y diversidad de alimentos que producen; las cuales han sido capacitadas, en cursos que ha programado la Casa de la mujer y algunas universidades que han desarrollado cursos de formación de empresas.

Con este grupo de mujeres surge la iniciativa, por parte de los docentes de la universidad Santo Tomás, para presentar el proyecto de investigación en la Casa de la mujer con asistencia de un grupo de 15 mujeres; esta ocasión se convierte en un espacio adecuado para el trabajo con emprendedores mediante la estrategia de desarrollo comunitario, fortaleciendo la relación entre la comunidad, el gobierno local y la Universidad, propiciando el desarrollo local a través de los talentos y recursos de los ciudadanos, familias y comunidades. Así se motivan algunas participantes de la Red de Mujeres y se logra reunir un grupo de 7 personas, para iniciar los actividades propuestas.

\section{Contexto local de Chapinero}

La localidad de Chapinero está ubicada al oriente de la ciudad. La ficha técnica turística de esta localidad (2008, pp. 8-10), indica que Chapinero se extiende desde la calle 39 a la calle 100, desde la Avenida Caracas hasta los Cerros Orientales. Limita con las localidades de Santa Fe, al sur; Teusaquillo y Barrios Unidos, al occidente; Usaquén, al norte, y con los municipios de Choachí y La Calera, al oriente. Al norte, limita con la calle 100 y la vía a La Calera, que la separan de la Localidad de Usaquén. Por el occidente, el eje vial autopista Norte-avenida Caracas la separa de las localidades de Barrios Unidos y Teusaquillo. En el oriente, las estribaciones del páramo de Cruz Verde, la "Piedra de la Ballena", los cerros Pan de Azúcar y La Moya marcan el límite entre la localidad y los municipios de La Calera y Choachí. El río Arzobispo define la frontera sur con la localidad de Santa Fe.

La monografía local (SDP, 2017, p.16) presenta una extensión de 3.800,9 hectáreas de territorio, de los cuales 1.093,5 hectáreas son de suelo urbano y 2.707,4 hectáreas de suelo rural. No posee suelo de expansión y con $3.364,0$ hectáreas, participa en un 2,9\% de la superficie urbana de la ciudad capital. (SDP, 2017, p.18), con una población de 126.591 (SDP, 2017, p.89) que representan el 1,6\% de los habitantes del Distrito Capital. Las cifras demográficas con proyecciones realizadas por la Secretaria Distrital de Planeación, hasta el año 2020. La Tabla No.1 presenta la población clasificada por sexo, las proyecciones de población muestran una disminución en la tasa de crecimiento. Los grupos adultos y adultos mayores son los únicos que cada vez tienen un peso mayor 
dentro del total de población, en contraste con las personas menores de 25 años que cada vez son un grupo poblacional menor, debido a la reducción de la fecundidad que experimenta la localidad.Según la Encuesta Multipropósito para Bogotá 2017, en la localidad se encuesta- ron 58.461 hogares, de los cuales el $45.3 \%$ son hogares de tipo nuclear, el $1.9 \%$ son hogares compuestos, el $10.6 \%$ son hogares de tipo extenso y el 42,2\% son de tipo unipersonal (SDP, 2017, p.147).

Tabla 1. Proyecciones de población según sexo.

\begin{tabular}{|l|l|l|l|}
\hline Años & Hombres & Mujeres & Total \\
\hline 2016 & 62.904 & 64.047 & 126.951 \\
\hline 2017 & 62.726 & 63.865 & 126.591 \\
\hline 2018 & 62.528 & 63.664 & 126.192 \\
\hline 2019 & 62.309 & 63.441 & 125.750 \\
\hline 2019 & 62.083 & 63.211 & 125.294 \\
\hline
\end{tabular}

Fuente. Alcaldía Mayor de Bogotá. Secretaría Distrital de Planeación. Proyecciones de población 2017- 2020.

En la Tabla No. 2 se presenta la clasificación de la población por estrato social, 2017, la po- blación en pobreza representa el 2.6\% del total de la población con una tendencia a disminuir.

Tabla 2. Clasificación de población por estrato social.

\begin{tabular}{|l|l|l|}
\hline Estrato social & Población & Porcentaje \\
\hline Estrato 1 & 1.251 & 1.0 \\
\hline Estrato 2 & 2.012 & 1.6 \\
\hline Estrato 3 & 8.425 & 6.7 \\
\hline Estrato 4 & 32.445 & 25.8 \\
\hline Estrato 5 & 19.617 & 15.6 \\
\hline Estrato 6 & 62.000 & 45.3 \\
\hline Población total & 125.750 & 100.0 \\
\hline
\end{tabular}

Fuente. Alcaldía Mayor de Bogotá D.C. Habitat en cifras diagnóstico Chapinero 2019. Tabla equipo de investigación.

El caso de Chapinero presenta la siguiente característica: el 2,2\% de la población se encuentra en pobreza multidimensional, en la que más se encuentran personas es en salud $(42,3 \%)$ y la dimensión que menos registra personas es la de vivienda (3,8\%). A nivel general el porcentaje de personas en pobreza multidi- mensional es bajo, en comparación a las otras localidades. El área urbana del piedemonte bogotano de los Cerros Orientales, se encuentra habitada por sectores populares, con poblaciones caracterizadas por conglomerados vulnerables y marginales, con necesidades insatisfechas. El Gráfico No. 1, muestra la situación 
de la población económicamente activa- PEA, la cual ascendió a 70.944 personas. La población ocupada en la localidad de Chapinero fue de 68.069 personas, frente a 2.875 personas desocupadas. El número de ocupados en Chapinero representa el 1,8\% del total ocupados en la ciudad y los desocupados representan el $0,9 \%$ del total en la ciudad.

Gráfico 1. Chapinero. Estructura del mercado laboral .

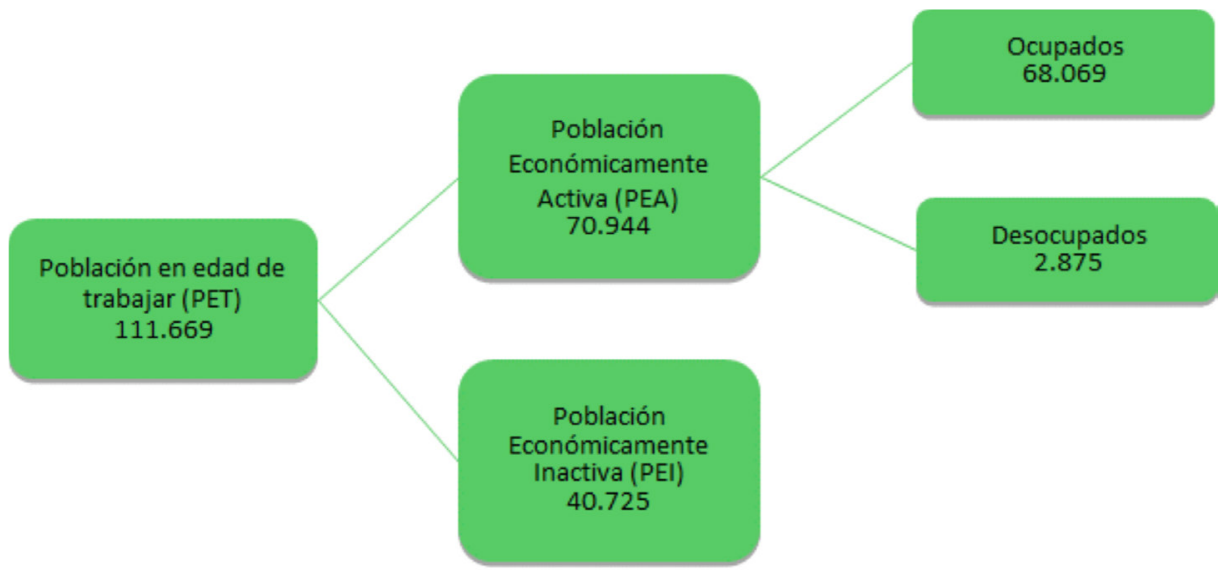

Fuente. Alcaldía Mayor de Bogotá. Diagnóstico localidad 2 de Chapinero. Secretaría Distrital del Planeación -SDP, Encuesta Multipropósito -EM 2017.

La investigación se adelantó en la localidad de Chapinero, debido a que allí se concentran los emprendimientos que han sido apoyados desde sus inicios por el Centro de Proyección Social, localizado en esta zona de Bogotá. La Universidad Santo Tomás reconoce las necesidades de la población que habita en su entorno como también los emprendimientos de grupos sociales que se han organizado con sus propios recursos, saberes y la informalidad de sus actividades. El Programa de Administración de Empresas, fortalece la asociatividad, apoya las iniciativas y los intereses colectivos, la ayuda mutua entre personas y organizaciones que buscan alternativas de mejorar sus ideas de negocios. Se contribuye con programas educativos para el desarrollo comunitario y responsabilidad social universitaria, que los habilita para gestionar proyectos sociales, mercadeo de sus productos y planes de negocios para la financiación de sus ideas de emprendimiento. La asociatividad como estrategia, aplicada a las organizaciones de menor tamaño, ha sido el elemento para enfrentar los cambios del mercado y sobrevivir en un entorno complejo.

El obstáculo encontrado en la caracterización se encuentra en la capacidad de la empresa, para lograr su estado de madurez, generalmente se encuentra un desequilibrio entre el estado inicial de la actividad emprendedora, en la que la falta de estudios, experiencia y desconocimiento en la mayoría de veces, presenta situaciones problemas de sostenibilidad en la puesta en marcha de las ideas de negocio. De esta forma la sostenibilidad es un aspecto que corre riesgos desde la misma actividad emprendedora y en donde los modelos de negocio para la generación de valor cobran especial relevancia. 
Trimi, Berbegal \& Jasmina (2012, p.1) Explican en su artículo, que mediante la investigación se avanza en la "comprensión de los desarrollos en emprendimientos emergentes en el diseño de modelos de negocios dentro del campo del espíritu empresarial". Aspecto que se encuentra débilmente conocido por los integrantes de los grupos que se forman dentro de la informalidad, por lo cual, no se le da la relevancia adecuada, en el establecimiento de los límites y cobertura de la organización y en la definición del producto / servicio que se ofrece. Esta es una actividad muy compleja para los emprendedores, sin embargo, según Trimi, Berbegal \& Jasmina (2012, p.1), "el modelo de negocio es una herramienta útil y el poder predecible de este contribuye con los [nacientes empresarios y con los establecidos] a tomar decisiones más informadas, lo que aumenta las posibilidades de éxito". Esta afirmación orienta los pasos iniciales en los que se avanza en el presente estudio con las siguientes preguntas orientadoras.

¿Cuál es el estado de cada uno de los emprendimientos?, ¿Qué tipo de modelo de negocio conocen y aplican?, ¿Cuáles son los factores del modelo de negocio, comunes?, ¿Cuáles son los de mayor presencia en la organización? y ¿cuáles de mayor importancia para la creación de valor y sostenibilidad?, con estas peguntas, se logra orientar el estudio que converge en la siguiente pregunta de investigación:

\section{¿Cuál es el modelo de negocio para el desarrollo de los emprendimientos en la localidad de Chapinero?}

\section{Objetivo general}

Identificar el modelo de negocio para el desarrollo de los emprendimientos en la localidad de Chapinero.

\section{Objetivos específicos}

1. Caracterizar el contexto de los emprendimientos en la localidad de Chapinero.

2. Identificar las características del grupo de mujeres que emprenden con ideas de negocio en la localidad.

3. Establecer las dificultades y barreras que han presentado en el desarrollo y estabilidad del negocio en la localidad.

4. Diseñar un programa de capacitación integral para el desarrollo de los negocios identificados.

5. Diseñar una propuesta de modelo de negocio para los emprendimientos de la localidad.

\section{Metodología}

La investigación es de carácter mixto, se combinan datos cualitativos con datos cuantitativos; por otra parte, la propuesta es también de tipo exploratorio e interpretativo y se desarrolla en el ambiente natural de la comunidad. Es 
exploratorio debido a que se pueden definir algunas variables de acuerdo con las teorías y generalizaciones de Hernández, Fernández y Baptista (2006, p.111) y tienen como objetivo la caracterización de los ideas de negocios reconocidos en la localidad de Chapinero y que funcionan en el contexto de la Alcaldía Local y familiarizar a los participantes en los temas del emprendimiento y modelo de negocio. Es interpretativa al analizar las opiniones, ideas, comentarios, creencia de los participantes, relativas a los temas definidos previamente. Este análisis complementa la descripción de los resultados. (p.113). Igualmente se aplica la investigación acción participativa o IAP, cuya finalidad es resolver problemas cotidianos e inmediatos, que según Álvarez Gayou (2003), citado por (Hernández, Fernández y Baptista, 2006, p. 706), es mejorar prácticas concretas, lo fundamental es proporcionar información que sirva de base para la toma de decisiones en programas, proyectos, cambios y reformas estructurales, lo que es coherente con los planteamientos de Sandini (2003, p.161) quien afirma, la IAP tiene como objetivo propiciar el cambio social, transformar la realidad y que las personas tomen conciencia de su papel en ese proceso de transformación. Para Cano, citado por Bernal (2006, p. 59) la IAP, "más que una actividad investigativa es un proceso eminentemente educativo de autoformación y autoconocimiento de la realidad", en el cual el grupo de emprendedoras tienen una participación directa en el contexto socio económico y cultural en que participan, para proponer e implementar las alternativas de solución a sus problemas y necesidades sentidas y estudiadas en las iniciativas de negocios.

La información cualitativa de los emprendimientos, se aborda mediante la entrevista semi- estructurada para el conocimiento de las experiencias del grupo de mujeres, quienes manifiestan las dificultades y las propuestas para su mejoramiento. La información cuantitativa se recolectó a partir de un cuestionario virtual, que se aplicó al grupo de mujeres, orientadas por un facilitador.

\section{Población}

En la selección de la población se aplicó el criterio no probabilístico, según Hernández, Fernández y Baptista (2006, p.566) se relaciona con las características de las personas que participan como población objeto del estudio. La selección fue voluntaria de las mujeres que participaron en la reunión de motivación y presentación del proyecto. Se tuvo en cuenta el criterio de los investigadores, relacionadas con las experiencias en negocios adelantados por las mujeres emprendedoras, un grupo de 7 mujeres, cada una con una actividad de negocio diferente, del sector de artesanías y alimentos, quienes se comprometen aportar su experiencia y son responsables de sus propios cambios, interactúan con los docentes que orientan y apoyan los procesos de identificación, caracterización y estado de los negocios,

\section{Instrumentos aplicados para la recolección} de información. Se aplican dos instrumentos para la recopilación de información:

Encuesta virtual para la identificación y caracterización de los emprendimientos. El objetivo se encaminó a conocer las características esenciales del grupo, productos que elaboran, actividades y servicios en desarrollo. Ver anexo No.1 
Panel de expertos. Se llevaron a cabo tres paneles de expertos como fuente primaria de la investigación, el proceso se efectúo en cuatro fases en la universidad Santo Tomas, con expertos reconocidos por su conocimiento y experiencia en prácticas y orientación de proyectos de emprendimiento del Programa de Administración de Empresas de la DUAD.

Primera fase: se hizo una revisión bibliográfica en la que se destacaron los autores en temas del modelo de negocios, emprendimiento, generación de valor, los factores fundamentales que los componen y las características que se destacan en cada postura de pensamiento.
Segunda fase: selección de expertos para el desarrollo de tres paneles como fuente primaria de investigación.

Tercera fase: se identificaron y valoraron las categorías fundamentales encontradas en los modelos de negocios revisados, la información resultante se analizó con el grupo de participantes.

Cuarta fase: diseño del modelo de negocios con explicaciones y valoración de emprendimientos.

Cuadro 1. Encuentros realizados con expertos.

\begin{tabular}{|c|c|c|c|}
\hline Fecha & Temáticas a tratar & Propósitos & Asistentes \\
\hline Julio 18/ 2018 & $\begin{array}{l}\text { - Contextualización del proyecto } \\
\text { a los participantes. } \\
\text { - Reconocimiento y presentación } \\
\text { de los asistentes al encuentro. } \\
\text { - Identificar sus apreciaciones } \\
\text { iniciales sobre los modelos de } \\
\text { negocio que apalancan empren- } \\
\text { dimientos. }\end{array}$ & $\begin{array}{l}\text { - Reconocimiento del proyecto } \\
\text { por parte de los asistentes. } \\
\text {-Reconocimiento de la ruta } \\
\text { de trabajo y propósitos de los } \\
\text { encuentros. } \\
\text { - Recoger las ideas iniciales de } \\
\text { los expertos relacionados con su } \\
\text { conocimiento sobre los modelos } \\
\text { de negocio. }\end{array}$ & $\begin{array}{l}\text { Dos expertos: Miguel Ángel } \\
\text { Cortes y Carlos Lozano. } \\
\text { Cuatro evaluadores: } \\
\text { Camilo Castaño, Blanca Rosa } \\
\text { de Peña, Yenny Jazmin Carrillo- } \\
\text { Auxiliar de investigación. } \\
\text { Hayr Alonso Gutiérrez - investi- } \\
\text { gador (se retiró de la universidad } \\
\text { en el mes de febrero de 2019). }\end{array}$ \\
\hline Agosto 15/ 2018 & $\begin{array}{l}\text {-Se presentan los resultados } \\
\text { de la revisión hecha sobre los } \\
\text { modelos de negocio orientados } \\
\text { a emprendimientos. } \\
\text {-Se recogen apreciaciones sobre } \\
\text { los modelos más pertinentes y } \\
\text { componentes más importantes. }\end{array}$ & $\begin{array}{l}\text {-Identificación de los modelos } \\
\text { de negocio más pertinentes para } \\
\text { el estudio y de los componentes } \\
\text { más importantes que permiten } \\
\text { orientar emprendimientos. }\end{array}$ & $\begin{array}{l}\text { Hayr Gutiérrez } \\
\text { presenta los resultados } \\
\text { de la revisión realizada. } \\
\text { Tres expertos: Miguel Ángel } \\
\text { Cortes, Carlos Lozano, Gabriel } \\
\text { Rodríguez. En el panel los } \\
\text { expertos señalan los modelos } \\
\text { más pertinentes. }\end{array}$ \\
\hline Agosto 28/ 2018 & $\begin{array}{l}\text {-Se presenta el modelo y la } \\
\text { propuesta de línea de base para } \\
\text { la validación por parte de los } \\
\text { expertos. }\end{array}$ & $\begin{array}{l}\text { - Validación de la línea de base } \\
\text { por parte de los expertos. }\end{array}$ & $\begin{array}{l}\text { Se presenta un gráfico con el } \\
\text { modelo de base. } \\
\text { Tres expertos: Miguel Ángel } \\
\text { Cortes, Carlos Lozano, Gabriel } \\
\text { Rodríguez. En el panel los } \\
\text { expertos orientan los } \\
\text { componentes del modelo más } \\
\text { apropiados. }\end{array}$ \\
\hline
\end{tabular}

Fuente. Equipo de Investigación. 


\section{Resultados de la investigación}

\section{Caracterización del grupo de emprendedoras de la localidad de Chapinero}

El grupo de emprendedoras presentan las siguientes características:

\section{a. Edad del grupo de emprendedoras}

- El grupo presenta edades entre los 33 años hasta los 54 años,

- Es un grupo joven con ideas nuevas para innovar y aprender.

- Las edades según el rango presentado en la Tabla No 3: el 42\% entre 30 y 40 años de edad; el $28 \%$ entre 41 y 50 años de edad y 28.6 entre 51 y 55 años de edad.

- Grupo motivado y con aspiraciones por mejorar y diversificar sus productos. para competir en el mercado localidad.

Tabla 3. Edades del grupo de emprendedoras.

\begin{tabular}{|l|l|l|}
\hline Edad & Cantidad & Valor \% \\
\hline $30-40$ & 3 & 42.8 \\
\hline $41-50$ & 2 & 28.6 \\
\hline $51-55$ & 2 & 28.6 \\
\hline Totales & 7 & 100 \\
\hline
\end{tabular}

Fuente. Encuesta aplicada por el grupo de investigación.

\section{b. Nivel educativo}

Presentan experiencia y conocimiento en las artesanías manuales, joyería elaborada en macramé, flores inmortalizadas, bisutería en collares, aretes, pulseras; en material reciclaje como: vitrales, productos en porcelana nicrom para lámparas, confiteras, empaques y otros productos similares. Productos alimenticios de panadería, pan integral, tortas y dulcería.

Tabla 4. Nivel educativo de emprendedoras.

\begin{tabular}{|l|l|l|}
\hline Nivel educativo & Cantidad & Valor \% \\
\hline Secundaria & 3 & 42.85 \\
\hline Educación técnica & 1 & 14.29 \\
\hline Universitaria & 2 & 28.57 \\
\hline No responde & 1 & 14.29 \\
\hline Totales & 7 & 100 \\
\hline
\end{tabular}

Fuente. Encuesta aplicada por el grupo de investigación.

La Tabla No.4 presenta el nivel educativo de las emprendedoras así:

- Con estudios en secundaria finalizados el $42.85 \%$, con el título de bachilleres.

- El 28.57\% con algunos semestres de pregrado, VII semestres del universitario.

- El 14.29\% Con estudios técnicos en enfermería y en construcción, programas del Sena

Presentan dificultades para vincularse a un trabajo estable, razón para aprender las manualidades y artesanías para abrir espacios de trabajo que les genere ingresos y que facilite su sostenimiento.

\section{c. Tiempo de vinculación a la iniciativa}

Las iniciativas de negocios han sido unipersonales, sólo una es de tipo colectivo en la que participan los integrantes de la familia. Los productos generados son bienes tangibles en 
el $86 \%$ de los casos y el 14\% restante está encaminado a la prestación de un servicio educativo en capacitación de manualidades y orientación espiritual. Con esta actividad una de las emprendedoras, en el lugar de residencia, tiene un salón con dotación apropiada para realizar talleres y capacitación en general, con una capacidad para 20 personas, así el proceso de capacitación del grupo se llevó a cabo en ese lugar, por comodidad y para cumplir con la programación sugerida con el grupo.

El tiempo de vinculación a la idea del negocio se observa en la Figura No. 2 , se destaca que el 42.8 \% de las emprendedoras hace más de tres años desarrolla la idea de negocio y el $14.3 \%$ son las más jóvenes que han emprendido la idea de negocio, menos de un año.

Figura 2. Tiempo de vinculación al negocio.

VINCULACIÓN A LA INICIATIVA DEL NEGOCIO

150

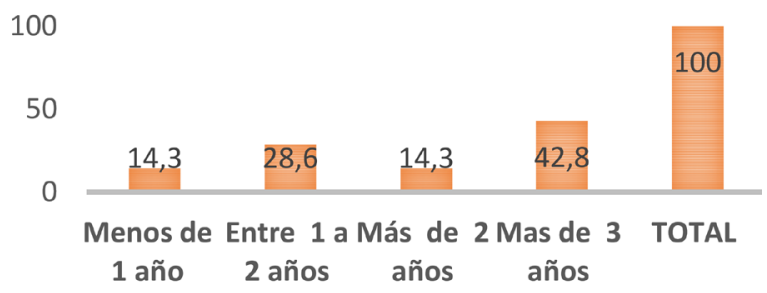

Fuente. Resultados de la Tabla No. 5 - Grupo de investigación.

\section{d. Pertenencia a un grupo social o comunitario}

Se pregunta si la persona que tiene la iniciativa, ¿hace parte de un grupo social o comunitario?

La respuesta refleja la identidad y pertenencia del $43 \%$ con el grupo familiar de base, el 29\% hacen parte de su comunidad, donde habita con su familia y el $14 \%$ hacen parte de la comunidad con la cual realizan sus actividades sociales. La Tabla No.5 muestra los resultados. De igual manera en la Figura 3, se observa la pertenencia a grupos sociales y comunitarios con los cuales hay una frecuente interacción en las actividades que se realizan. En este aspecto es importante resaltar que todas cuentan con teléfono celular, utilizan el portal Web con la Red de Mujeres de Chapinero, medio interactivo que utilizan para comunicarse, programar encuentros en ferias, cursos de capacitación y formación, eventos de promoción de los productos y servicios que ofrecen.

Tabla 5. Pertenencia a un grupo social o comunitario.

\begin{tabular}{|l|l|l|}
\hline $\begin{array}{l}\text { Grupo social o } \\
\text { comunitario }\end{array}$ & Cantidad & Valor \% \\
\hline Comunidad & 1 & 14 \\
\hline Familiar & 3 & 43 \\
\hline $\begin{array}{l}\text { Comunidad y } \\
\text { familiar }\end{array}$ & 2 & 29 \\
\hline Otro grupo & 1 & 14 \\
\hline Total & 7 & $100 \%$ \\
\hline
\end{tabular}

Fuente. Encuesta aplicada por el grupo de investigación.

Figura 3. Pertenencia a un grupo social o comunitario.

Pertenencia a un grupo social o comunitario

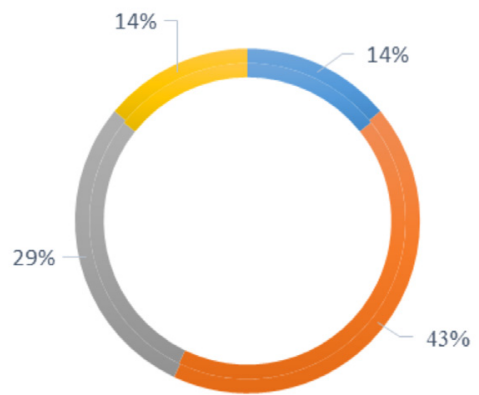

=Comunidad $=$ Familiar $=$ Comunidad y familiar $\equiv$ Otro grupo Fuente. Resultados de la Tabla No. 6 - Grupo de investigación. 


\section{e. Participación en organizaciones sociales}

Los aspectos organizacionales presentes en la vida social y cotidiana de las emprendedoras son aspectos importantes para el desarrollo de la pertenencia y participación social en ellos. La organización social facilita a las personas compartir opiniones, valores, visiones de mundo, intereses e inquietudes.

La organización social facilita a las personas compartir opiniones, valores, visiones de mundo, intereses e inquietudes. En el caso del grupo de emprendedoras, sus experiencias en las actividades productivas, las relaciona con los mercados, los clientes y en algunas oportunidades el desarrollo de emociones y motivaciones, las impulsa a unirse para lograr sus objetivos, aspiraciones personales y oportunidades para fortalecer las relaciones de amistad y de trabajo.

Tabla 7. Participación en organizaciones sociales.

\begin{tabular}{|l|l|l|}
\hline Organización social & Cantidad & Valor \% \\
\hline Grupo religioso & 3 & 43 \\
\hline Acción comunal & 2 & 29 \\
\hline Ninguna asociación & 1 & 14 \\
\hline Otras & 1 & 14 \\
\hline Total & 7 & 100 \\
\hline
\end{tabular}

Fuente. Encuesta aplicada por el grupo de investigación.

Al estar organizadas en la Red de Mujeres y contar con un lugar de encuentro como es la Casa de la Mujer, son mecanismos que facilitan la organización social. Estas organizaciones surgen y se adaptan a las necesidades del ser humano, es por ello que continuamente aparecen y desaparecen o se modifican, con el propósito de dar respuesta a sus necesidades o a una problemática que las afecta.
- En el grupo el $43 \%$ pertenecen a una asociación religiosa

- El 29\% a la asociación u organización comunitaria, la acción comunal del barrio

- El $14 \%$ a ninguna y otras no manifestaron su inclinación asociativa.

\section{f. Dificultades en el proceso de emprendimiento}

Según un estudio de la multinacional Boston Consulting Group (2018, p.1) en artículo publicado en la revista Portafolio, las principales dificultades de los emprendedores se presentan en la ambigüedad de la definición del modelo de negocio, es así que el emprendedor es "incapaz de diferenciarse de otros negocios sociales del país que, si bien adoptan prácticas responsables, no están enfocados en generar valor social". Otras dificultades encontradas e $\mathrm{n}$ este documento, se relacionan con:

- La falta de un modelo de negocio rentable que garantice la sostenibilidad, debido a que en ocasiones no se cuenta con un modelo de negocio estructurado.

- El empresario no tiene claridad sobre el costo y la rentabilidad de sus productos y no realiza un análisis financiero y de capacidad para evaluar la viabilidad de una inversión.

- Se recomienda que las inversiones en maquinaria y equipo deben efectuarse tras el análisis de la capacidad, la identificación de los principales cuellos de botella en el proceso productivo y el 
análisis del tiempo requerido para recuperar la inversión.

El estudio adelantado por el equipo de investigación, al grupo de emprendedoras, manifestó las dificultades que se presentan a continuación y se expresan en la Figura No. 4.

- Falta de recursos económicos el 30 \% de emprendedoras.

Cada una de las dificultades señaladas en el siguiente párrafo, tiene un puntaje del 14\%, dando así, igual de importancia a cada una de las variables anunciadas.

Figura 4. Dificultades en el proceso de emprendimiento.

\section{Dificultades en el proceso de emprendimiento

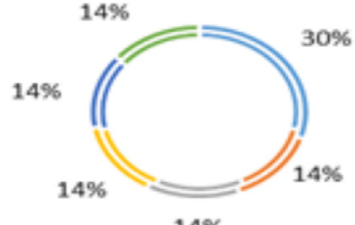 \\ $14 \%$ \\ = Dificultades encontradas \\ = Trabajo individual \\ = Trámites legales del negocio \\ Fuente. Resultados de encuesta aplicada y analizada por el grupo de investigación.}

- Recursos Económicos

= Estrategia de ventas

- Las dificultades de publicitar el negocio a través de las redes sociales.

- La realización del trabajo de manera individual.

- Carece de estrategias en ventas y por lo tanto de retención de clientes.

- Los trámites con el estado son muy engorrosos, aspecto que desmotiva a la constitución de organizaciones empresariales.

\section{Programa de capacitación}

Con la metodología de investigación acción participativa (IAP), y talleres participativos, se trataron temas de emprendimiento e innovación, los elementos fundamentales de un modelo de negocio y la práctica a través de la evaluación del modelo de negocio, CANVAS aplicado de manera general, pero cada participante lo aplicó a su emprendimiento específico. Los encuentros con el grupo de emprendedoras se desarrollaron con una duración aproximada de 2 a 3 horas, en la casa de una emprendedora que disponía de la infraestructura con un salón de clase, estas se llevaban a cabo de 9.00 a 12 a.m, los días martes. El programa se desarrolló en 40 horas académicas, distribuidas en 20 horas de teoría y ejemplificación de casos, 10 horas de práctica y la evaluación cada emprendimiento y en 10 horas se analizó, en grupo, los ajustes necesarios a realizar en cada emprendimiento. Este proceso fue enriquecedor, porque cada una tuvo la oportunidad de conocer las sugerencias y recomendaciones para mejorar el negocio, del equipo de compañeras y los investigadores que acompañaron el proceso. 
Cuadro 2. Temas tratados en el programa de capacitación.

\begin{tabular}{|c|c|c|}
\hline \multicolumn{3}{|c|}{ FORMACION INTEGRAL } \\
\hline Valores & Cultura innovadora & Desarrollo empresarial \\
\hline $\begin{array}{l}\text { Autoestima, deseo de superación. } \\
\text { Libertad - autonomía. } \\
\text { Sentido de pertenencia al grupo social, } \\
\text { comunidad. } \\
\text { Los retos del trabajo en equipo. } \\
\text { Solidaridad - asociatividad. } \\
\text { Valores comportamentales ética, transpa- } \\
\text { rencia y honestidad responsabilidad, lealtad } \\
\text { compromiso. } \\
\text { Actitud mental positiva, frente a los riesgos } \\
\text { y complejidades del entorno. } \\
\text { Seguridad y confianza para el cambio. }\end{array}$ & $\begin{array}{l}\text { Estímulo a la investigación. } \\
\text { Aprendizaje permanente. } \\
\text { Fortalecimiento de los activos intangibles, el } \\
\text { capital del conocimiento. } \\
\text { Conocimiento con nuevas ideas, producción } \\
\text { innovadora. } \\
\text { Fortalecimiento de los productos o servicios } \\
\text { con valor diferenciador y competitivo. } \\
\text { Innovación a partir de la identificación de } \\
\text { alternativas y oportunidades de cambio } \\
\text { crecimiento, fortalecimiento. } \\
\text { Desarrollo de habilidades creadoras e } \\
\text { innovadoras. }\end{array}$ & $\begin{array}{l}\text { Trabajo integrado, asociativo o cooperativo. } \\
\text { Responsabilidad social empresarial. } \\
\text { Aplicación de capital de socios como fuente } \\
\text { de recursos primarios. } \\
\text { Articulación del emprendimiento con las } \\
\text { empresas para la formación de redes, } \\
\text { alianzas estratégicas y servicios de asesoría } \\
\text { especializada. } \\
\text { Capacidad de tomar decisiones en la gestión. } \\
\text { Modelo CANVAS y sus componentes aplica- } \\
\text { ción a un modelo de negocio social. } \\
\text { Componentes del modelo de negocio y } \\
\text { su aplicación para la evaluación de la idea } \\
\text { emprendedora. }\end{array}$ \\
\hline
\end{tabular}

Fuente. Elaboración equipo de investigación.

\section{Marco teórico y referencial a partir de la revisión bibliográfica de los investigadores, la experiencia y conocimiento de los expertos panelistas para modelo de negocio}

\section{Referentes conceptuales}

\section{- Conceptos de emprendimiento e innovación}

En el mundo actual las condiciones laborales se encuentran más limitadas y las exigencias para acceder son cada vez más difíciles, ha cambiado el criterio, para la vinculación de personas que hacen parte de los desempleados y población marginal; el concepto de emprendimiento cobra importancia para la sociedad, como un tema de interés, actual y necesario de tratar a nivel universitario, del Estado y el sector privado.

La problemática planteada, ha generado en las personas la necesidad de crear y organizar sus propios negocios, que les genere ingresos para su supervivencia. Gerencie.com (2018, p.1) afirma "pasar de ser empleados a ser empresario, [contribuye a plantear solución al problema. Esto se logra] si la persona tiene un espíritu, emprendedor, [si asume los riesgos del negocio], renunciado a la estabilidad económica de un empleo estable".

De acuerdo con Gerencie.com (2018, p.1) el emprendimiento: proviene del [término] francés "entrepreneur, [que significa] pionero, y se refiere a la capacidad de una persona para 
hacer un esfuerzo adicional por alcanzar una meta u objetivo, siendo utilizada también para referirse a la persona que iniciaba una nueva empresa o proyecto". En todo este proceso las personas mejoran y generan nuevas capacidades y habilidades para lograr productos de calidad, sin embargo el ser humano nunca está satisfecho de sus logros y frente a sus propias inquietudes crea e innova con ideas nuevas, para lograr las metas hacia el futuro deseable.

El liderazgo es uno de los elementos del emprendimiento, al respecto Vainrub (2009, p.9), cita a Turker, McCarthy y Benton (2002), quienes indican las condiciones que desarrolla un líder, "por virtud de sus propios atributos, estimula a otros para alcanzar alguna meta, el líder tiende a enfocarse en sus propias visiones, y se esfuerza en convertir esas visiones en realidades", estas condiciones se presentan en empresarios, personas, comunidades, que desarrollan objetivos diferentes, con el propósito de procurar mejoramiento del nivel de vida, las nuevas formas de búsqueda de alternativas de solución a sus problemas y necesidades, para llevar a cabo la alternativa más viable que facilite el mejoramiento de la problemática planteada. Por lo anterior, la actitud y aptitud que demuestra una persona para iniciar y desarrollar un nuevo proyecto a través de ideas y oportunidades en cualquier campo de actividad en la organización, equipo de trabajo o el de una persona de manera individual, se caracteriza porque el emprendedor asume riesgos con el objeto de generar oportunidades de crecimiento económico, que le ofrece cambios positivos a su empresa familia o para el mismo. Según Global Entrepreneurship Monitor, GEM (2013, p.24), cita a McMullen y Shepherd (2006), sostienen que "los individuos reaccionan primero a las oportuni- dades cuando las ven, solo luego hay consideraciones sobre la conveniencia y viabilidad" Se puede marcar la diferencia cuando el emprendedor confía en sus propias capacidades y puede iniciar actividades de manera independiente. Esto apoya la idea de que existe una relación entre actitudes, actividades con una mezcla de factores individuales, sociales y del entorno.

Al respecto, Varela (2009, p.30) considera que "el entorno puede ser un gran motivador: las amistades, los familiares, figuras públicas, insatisfacción con el trabajo, [el desempleo]". De acuerdo con lo anterior, es necesario analizar el entorno, sus posibles cambios mirando hacia el futuro, porque esta es una de las variables que se olvidan al momento de viabilizar una idea innovadora, o al formular el modelo de negocio, que motiva a desarrollar la idea de manera viable. En conferencia dictada por Gómez (agosto 14, 2019), en la universidad Santo Tomás, titulada "Big data e inteligencia artificial", se confirma la importancia del ecosistema del emprendedor, es decir el entorno en el que se visualizan todos los factores que afectan el desarrollo de una idea de negocio, lugar donde se va a emprender, los factores del mercado, la tecnología para la empresa a conformar, conocer sobre la actividad empresarial y especialmente cuando se inicia con un pequeño emprendimiento, ser autogestionario, autocritico, crear alianzas con otros y con los grupos de trabajo al interior de la organización y con otros del entorno.

Gómez (2019), cita a Laloux Frederie, para desarrollar la idea de emprendimiento al interior de las empresas, para lo que es importante la humanización en las organizaciones, describe: el patrón de evolución organizacio- 
nal, se fundamenta en el trabajo de varios pensadores en un campo definido teoría del desarrollo. "Una de las ideas básicas es: las sociedades humanas y los individuos, no crecen de manera lineal, sino en etapas-niveles de creciente madurez, conciencia y complejidad" (2017, p.1) varios pensadores a estos estados organizacionales les han dado nombres y los designan con colores de acuerdo a su grado de desarrollo en la gestión de las organizaciones, en este contexto se enfatiza en la creatividad de la gestión y la innovación permanente.

Según Varela (2014, p.9) "La identificación de oportunidades y la solución innovadora se relaciona con el concepto 'cambio', debido a la acción del ser humano, quien ha introducido formas de alterar cualquier cosa introduciendo algún elemento que lo va distinguiendo de los demás, esta creación de nuevas ideas de cambio es lo que se llama innovación". Sin embargo el cambiar alguna cosa, un proceso, una organización y lo más difícil cambiar el sentido de la vida, la forma de pensar, es vital para emprender e innovar, porque el ser humano siente temor, inseguridad, riesgo, incertidumbre que limita el accionar de la persona.

En la actualidad el mundo se mueve en "dilemas de riesgo, / recompensa, (Varela, 2014), asegura "es importante comprender que frente a los riesgo propios del cambio, hay una posibilidad importante de lograr recompensas atractivas". Con estos fenómenos se mueve el mundo todos los días. El siglo XXI, se ha desarrollado con cambios acelerados de manera radical y necesaria para el mejoramiento permanente, aquellos que no se suban a esta dinámica, están llamados al fracaso.
Rolf Smith citado por Varela (2014, p.10) afirma que "para poder sobrevivir debemos cambiar continuamente, debemos cambiar la forma en que percibimos el mundo, cambiar la forma de pensar". Lo anterior, se puede lograr introduciendo actitudes, valores, respuestas y conocimiento compartido, amable, solidario, de cooperación y ayuda mutua, pensando en el crecimiento y cambio de los demás.

El Manual de Oslo (2005, p.21) documento orientador de la innovación indica "la innovación se encuentra en cualquier sector de la economía, incluyendo el de servicios públicos, tales como la salud o la educación" este manual está diseñado para tratar la innovación en el ámbito empresarial. En un contexto más amplio, Romero y Pinzón (2017) proponen una definición de innovación en la que esta se entiende como la acumulación de capacidades en un contexto específico para el aprovechamiento de una novedad, siendo especialmente relevante el contar con capacidades suficientes que permitan lograr la consolidación de procesos innovadores (Romero, 2018).

Las organizaciones realizan cambios de manera permanente, en los productos que ofertan, los procesos para darle mayor valor a lo que elaboran, captan conocimiento y experiencia y en general a todo aquello que produce cambios significativos en la organización por ideas innovadoras y que influyen en las actividades económicas y en los resultados de la empresa. Recomienda que para desarrollar la innovación destaca la importancia que tienen las instituciones de educación como instrumento para hacer posible que los individuos de una sociedad -y ella misma en su conjunto- sean capaces de desplegar y aprovechar su talento. 


\section{- Concepto de propuesta de valor en el negocio}

Alcaraz (2011, p. 31) | cita varios autores al tratar el concepto de generación de valor en el negocio, para explicar la importancia de este término, referencia a Zimmerer (2005), quien afirma "elaborar y desarrollar un plan estratégico es crear una ventaja competitiva, agregar factores que identifiquen y diferencien a la compañía de sus competidores y le den una posición única y superior en el mercado". La creación de valor se puede reconocer como la de sus competidores. Cita igualmente a Metzgel y Donaire (2007) quienes definen la propuesta de valor, como la mezcla única de productos, servicios y valores agregados que la empresa ofrece a sus clientes. Comenta sobre la investigación de mercados como uno de los aspectos, que contribuye a la toma de decisiones por anticipado. Frente a este factor, la competencia y definir cómo se quiere ser y cómo se espera que el mercado perciba a la empresa, en términos de productos (bienes y servicios) y de su modelo de negocios en general. Cita igualmente Alcaraz (2011, p.31) la definición de Fayolle (2007), quien la menciona de manera global.

El emprendimiento es un proceso dinámico de creación de valor incremental, creado por individuos que asumen riesgos [en varios aspectos], como equidad, tiempo, dedicación, compromiso profesional al negocio, para darle valor al producto,(proceso) o servicio, en este sentido Fayolle, le da importancia al individuo y la creación de valor, lo cual indica que la creación de valor está relacionada con la innovación y la ventaja competitiva, lo cual se explica que la noción de valor, entendida como valor útil para el consu- midor final, siempre está ligada a estas propuestas.

La mayoría de las organizaciones o empresas que tienen como oferta un producto o servicio, no tienen claridad de la propuesta de valor que ellas tienen, es importante establecer las características de la propuesta de valor. La construcción de una propuesta de valor debe señalar, los beneficios que la empresa ofrece al cliente a través de cierto producto, proceso o servicio y la empresa debe ser capaz de responder a la pregunta del consumidor: $i$ Por qué debería comprarle a usted? El concepto de valor fue originalmente difundido por Porter (1985), citado por Alcaraz (2011, p. 32) con el nombre cadena de valor, que permite identificar los procesos a seguir dentro del negocio, lo cual ayuda a determinar los indicadores para su medición y necesidades de recursos para el logro de los objetivos y metas.

Se concluye que la propuesta de valor es el factor que influye en el usuario o cliente de bienes y servicios para que se incline hacia una determinada empresa, porque su oferta le satisface sus necesidades o contribuye a resolver su problemática. La propuesta de valor es el diferenciador o prototipo del producto o servicio que la empresa o un emprendedor ofrece a sus usuarios, clientes o consumidores.

\section{Modelo de negocio}

El modelo de negocio describe la forma en que una organización crea, captura y entrega valor, en las diferentes actividades que adelanta y que son importantes para el éxito de la empresa. Tales como: infraestructura institucional, la misión, visión, políticas y estrategias que orienta, formas de financiación y trato con los clientes. 
Ferreira $(2015$, p. 71$)$ cita a Peter Drucker al referirse al emprendimiento, se puede entender como aquella actitud y aptitud de la persona que le permite afrontar nuevos retos, nuevos proyectos; es un acto que hace uso de los recursos con una capacidad para la creación de riqueza (Drucker, 1985), por lo cual, se usa, para iniciar determinadas actividades que conlleva al origen de un negocio, aplicando un modelo en la que se orientan la capacidad del emprendedor para implementar y operar empresas nuevas. Continúa Ferreira (2015, p.72). Cuando hace referencia a (Osterwalder \& Pigneur, 2010), quienes expresan “Un modelo de negocio describe las bases sobre las que una empresa crea, proporciona y capta valor".

Por otro lado, Osterwalder (2004 p.15), al referirse a un modelo de negocio afirma:

Es una herramienta conceptual que contiene un conjunto de elementos y sus relaciones y Permite expresar la lógica de una empresa de ganar dinero. Es una descripción del valor de una empresa que ofrece a uno o varios segmentos de clientes y la arquitectura de la empresa y su red de Socios para crear, comercializar y entregar este valor y capital de relación, con el fin de generar ingresos rentables y sostenibles.

La figura No. 5, muestra los componentes del modelo CANVAS (Osterwalder, 2004), este modelo se compone de nueve bloques de construcción básicos, que muestran la lógica de cómo una empresa tiene la intención de hacer dinero. Los nueve bloques observados cubren las cuatro áreas principales de una empresa: clientes, oferta, la infraestructura y la viabilidad financiera. El modelo de negocio sirve de base para una estrategia que se implementa a través de las estructuras de organización, procesos y sistemas.

Figura 5. Modelo CANVAS. Componentes que estructuran el modelo.

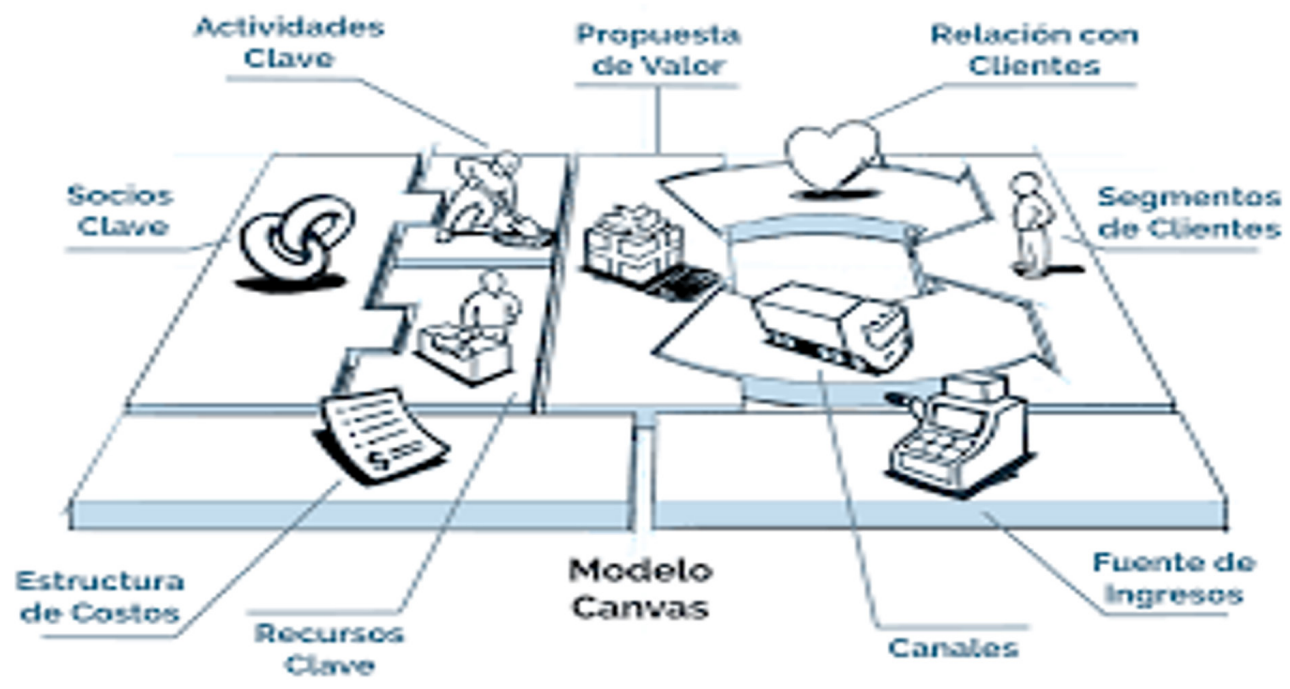

Fuente. Recuperado de: http://blog.factura.com/2016/05/17/introduccion-al-modelo-canvas-modelo-de-negocio/ 
Los nueve componentes del modelo:

- La propuesta de valor, se ubica en el centro, de la figura atrae a los clientes, por lo general se trata de productos o servicios con un diferenciador.

- Segmento de clientes, o las personas a los que se les dirige la oferta (producto o servicio).

- Canales de distribución, a través de los cuales se accede a los clientes, se ofrece la propuesta de valor.

- Tipo de relaciones que se establecen con el o los segmentos de clientes, y formas de comunicación.

- Fuente de ingresos que se recibe por la propuesta de valor que se ofrece.

- Recursos clave que requiere la organización para hacer funcionar el negocio (incluyen recursos, financieros, humanos, físicos, intelectuales), como se puede apreciar son la base sobre las que se construye.

- Actividades clave, las que se realizan para producir la oferta a partir de los recursos.

- Red de aliados, conformada por la red de proveedores y agentes con quienes se establecen relaciones para apalancar los recursos y actividades que a su vez permitan construir o complementar la propuesta de valor.
- Estructura de costos, fundamentada en el listado de costos más significativos: recursos, actividades, red de aliados y relación con los demás bloques.

\section{Modelo de negocio CANVAS social para emprendimientos comunitarios o sociales}

El Canvas también ha sido introducido para desarrollar emprendimientos sociales, es una herramienta diseñada para orientar, ayudar y contribuir con los emprendedores sociales a interpretar, entender y construir modelos de negocio para sus proyectos empresariales con impacto social. Ginés Haro (sf), adicionó algunas herramientas para crear un CANVAS social (oservar la Figura No. 6, donde se establecen los diferentes componentes, se mencionan los que más se destacan en este modelo de negocio social). 
Figura 6. Modelo CANVAS social.

\section{CANVAS DE MODELOS DE NEGOCIO SOCIAL}

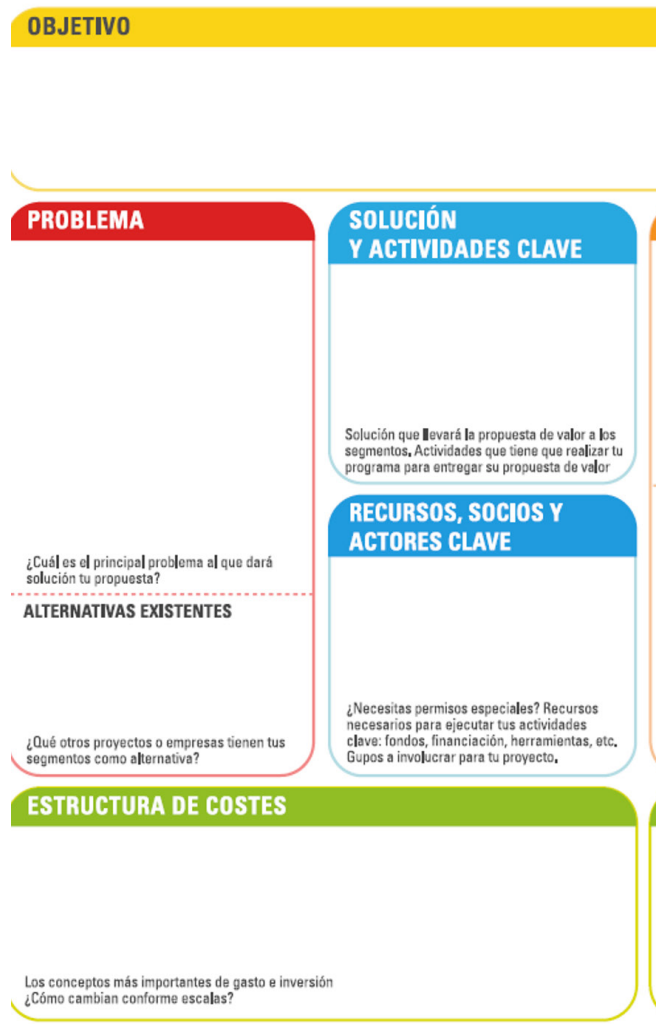

www.movimientoidun.com

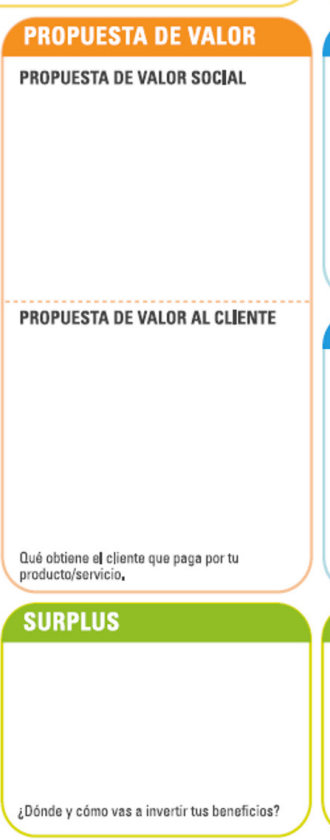

iอบับ
IMPACTO

Define tu impacto social o medioambiental y los beneficiarios de cada aspecto.

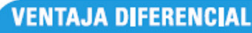

SEQMENTOS

CLIENTE ¿Por qué tendra éxito este proyecto? ¿Qué
te hace tu provecto único y tu competencia

CANALES

¿Quién es la persona u organización que paga por tu servicio/producto?

BENEFICIARIO ¿Cómo te comunicas con tus clientes y
beneficiarios? ¿Cómo entregas tu producto/ INGRESOS

Describe tus fuentes de ingresos en \%

Desarrollado por Ginés Haro Pastor Diseño: Manuel Espino () (1) (()

Fuente. Haro Pastor Ginés (sf).

Impacto: define el impacto social y medioambiental, así como los beneficios en cada aspecto. Es importante que incluya los indicadores base que se utilizará para medir los resultados y que servirán para evaluar si está logrando el cambio propuesto con el emprendimiento social.

Problema: ¿cuál es el principal problema al que dará solución la propuesta? Hay problemas específicos, a los que se enfrentan los clientes y/o beneficiarios que no son los generales que se podrían plantear en la sección Objetivo.
Analizar qué alternativas hay para solucionar el problema.

Ventaja diferencial: ¿Por qué tendrá éxito este proyecto de emprendimiento social? ¿Qué hace del proyecto algo único que la competencia no podrá copiar?

Surplus: ¿Cómo utilizará los beneficios del emprendimiento social? ¿Dónde y cómo lo va a invertir? El autor Vial (2016) afirma: las particularidades de un modelo de negocio en emprendimientos sociales son importantes de 
atender, debido a que remiten a analizar otras variables adicionales a las que ya se incluyen los modelos tradicionales. Los emprendimientos sociales se diferencian de otros y la teoría de estos emprendimientos pueden enriquecerse, el emergente modelo CANVAS que ha sido aplicado para adaptarlo al caso de los emprendimientos sociales.

Morris, Schindehutte \& Allen, (2005, p.730) citado por Andersen, Ljungkvist \& Svensson, (2015), estos autores consideran un modelo compuesto por 6 componentes o áreas de decisión:

1. la oferta, en la que se describe su rol en la producción, cómo crea valor la organización y la forma como se configura. 2. El mercado describe a los consumidores y define la posición en la cadena de valor 3. Economía, vista como el factor primario, también relacionado con las fuentes de renovación. 4. factores personales, se refiere a las ambiciones del empresario en términos de tiempo y crecimiento 5. capacidades internas considera la experticia y habilidades de la empresa, puede incluir el desarrollo de productos, la innovación y 6. la estrategia competitiva, la cual remite a preguntar ¿Cómo está posicionada la compañía en el mercado? ¿Cuál es la estrategia construida? En la diferenciación, se tiene en cuenta la de más bajo costo.

Propuesta de modelo de negocio para los emprendimientos de la localidad de Chapinero

Con los resultados de los análisis de los componentes de los modelos de negocios, se consultó y se pidió el apoyo al experto en el tema, Lozano (2019), quien escribió apartes del modelo de negocios, fundamentándose en los resultados del panel de expertos con su partici- pación activa, la consulta de autores realizada, la interacción con el equipo de investigación y la evaluación de cada emprendedora de su negocio, aporta ideas muy claras sobre las problemática y necesidades en los medios donde desarrollan sus ideas de negocios. El grupo de mujeres manifestó la utilidad de la herramienta de acuerdo con las mejoras en cada uno de los proyectos personales que desarrollaron y promocionaron en diferentes espacios como: Feria Empresarial de la USTA, realizada en noviembre de 2018, feria realizada por la Red de Mujeres de Chapinero y otros eventos programados por la Alcaldía Local de Chapinero. El esquema propuesto para el modelo de negocio, presenta los principales factores que es necesario tener en cuenta para desarrollar emprendimientos con comunidades y pequeños negocios:

Se diseñó un modelo de negocios, resultado de diversas posturas teóricas, la experiencia de los profesionales participantes en los paneles de expertos y el análisis del tema en talleres de capacitación con emprendedoras. 
Figura 7. Modelo de negocio para emprendedores.

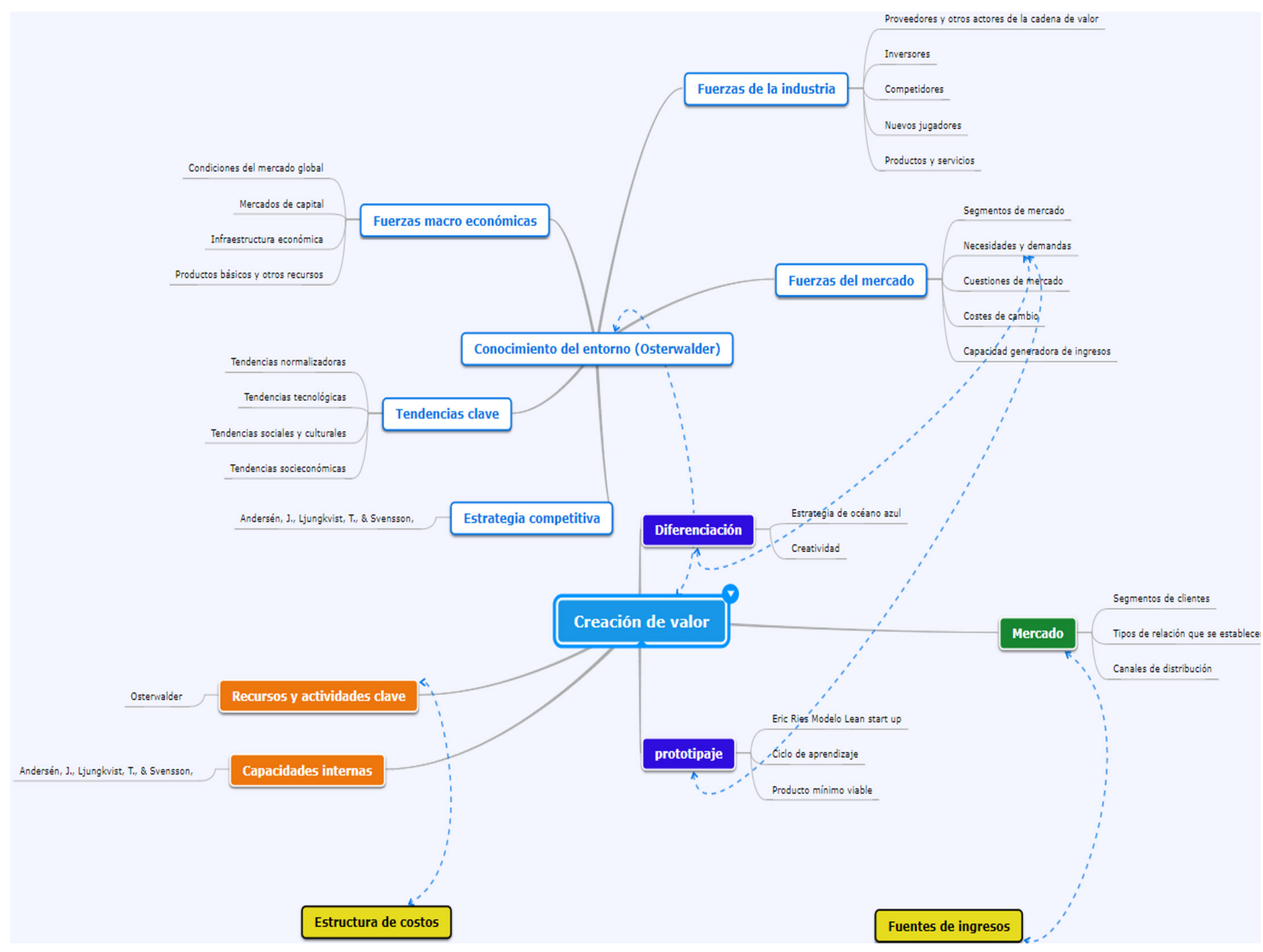

Fuente. Diseño del equipo de investigación.

El esquema propuesto para el modelo de negocio, presenta los principales factores que es necesario tener en cuenta para desarrollar emprendimientos con comunidades y pequeños negocios, y nace del proceso de investigación participativa desarrollada en el presente estudio (ver Figura No.7), se tomó como base de estudio el modelo CANVAS.

Los componentes definidos para incluir en el modelo de negocios son los siguientes:

\section{Fuerzas macroeconómicas}

Las fuerzas macroeconómicas son todos aquellos aspectos que de manera global afectan el negocio. Su desconocimiento para el caso de pequeños negocios, implica su desaparición. Es importante identificar los efectos que puede generar el intercambio comercial con otros países, dado que en la actualidad la competencia no es solamente local, o nacional, sino también con empresas multinacionales, fran- 
quicias, clúster y grandes empresas en diversos países interesadas en poder obtener un beneficio en el mercado de las micro, pequeñas y medianas empresas, la gestión eficiente de estos emprendimientos se refleja en la producción, uso de materiales y las decisiones operativas que construyen la forma de materializar y responder a las metas planteadas en los procesos de planificación. Las decisiones de tipo operacional se toman desde el contexto dado por la estrategia definida.

\section{Fuerzas de la industria}

El estudio evidenció que en los emprendimientos analizados no se contempla el análisis del entorno, ocasionando que se establezca como el problema de acuerdo a las respuestas dadas por las empresarias a la hora de desarrollar ventajas competitivas para sus negocios. Esta fue una recomendación dentro del proceso de desarrollo de los paneles de expertos. El análisis del entorno incorpora elementos, con los cuales se construye la competitividad basados en las fuerzas de Porter (1979), que permite establecer la rivalidad en una industria y la intensidad de la competencia con lo cual se identifican oportunidades para el entorno. Este modelo analiza la capacidad de negociación de los proveedores, rivalidad entre los competidores, facilidad de acceso a mercados, poder de negociación de los clientes y la amenaza de productos sustitutos. En este modelo además se resalta la importancia del talento humano, los procesos de capacitación del equipo de trabajo, que son nulos en micro y pequeñas empresas, por lo que se requiere por parte de los empresarios contemplar las bondades del Servicio Nacional de Aprendizaje (SENA), institución que través de la formación técnica, tecnológica y complementaria, capacita para el trabajo en las diferentes áreas que requiere la empresa, acompaña y asesora los procesos para ser más competitivas. De igual manera, la Universidad es un actor muy importante en este proceso; desde Responsabilidad Social Universitaria y proyectos de investigación, se pueden desarrollar alianzas estratégicas con los empresarios de las regiones y localidades,

\section{Fuerzas del mercado}

Se define el mercadeo como el conjunto de actividades enfocadas a satisfacer las necesidades de los clientes. Para poder desarrollar este mercadeo es necesario incorporar los elementos analizados anteriormente y que permiten identificar cual es el estado del negocio, en cuanto a la posición del sector, tanto en el presente, como en el futuro.

En este punto es importante evaluar la gestión de mercadeo en cuanto a:

- ¿Mi canal de distribución es el más adecuado para mi producto o servicio?

- ¿El producto o servicio incorpora la propuesta de valor de mi negocio?

- ¿Desarrollo estrategias de promoción y publicidad acordes al canal de distribución y tipos de clientes?

- ¿El precio de venta de mi producto es competitivo en cuanto a que toma como referencia a los clientes, la competencia y los costos?

- ¿Planeo las ventas de acuerdo a la información del mercado y capacidad de producción de mi empresa? 
Un punto importante en el análisis de las

fuerzas del mercado es establecer el segmento o segmentos que espera cubrir la empresa y una vez identificados, analizar las tendencias de consumo, la competencia, cuantificar la demanda con el fin de poder establecer oportunidades para el negocio.

\section{Tendencia clave}

Los patrones de comportamiento en los mercados, establecen el tipo de liderazgo que se debe desarrollar en la empresa. Estos patrones están muy influenciados por la normatividad legal que aplica a los negocios, la tecnología, los aspectos culturales y sociales y las condiciones socioeconómicas.

A nivel legal hay elementos que el negocio no puede olvidar como lo son la constitución de la empresa, los permisos y licencias para poder desarrollar la actividad productiva, la legislación laboral y la normatividad ambiental. Su conocimiento y aplicación en el negocio puede evitar sobrecostos relacionados con multas, demandas legales relacionadas al producto o al desarrollo de la actividad productiva, en zonas donde no se pueden desarrollar.

La tecnología se define como la mejora en los procesos de producción que permite la optimización de tiempos, de recursos y costos. La incorporación de los avances tecnológicos, no solamente abarcan el proceso de producción, sino los resultados de la investigación de la empresa, en cuanto al consumo de sus productos, disposición de compra y comportamiento de la demanda.

\section{Conclusiones}

Las características más destacadas del grupo de emprendedoras relativamente joven, en un $42.8 \%$, y el $57.2 \%$ son mujeres adultas con una mayor experiencia en su trabajo artesanal y manual. El 57\% de este grupo ha desarrollado en mejor forma, la iniciativa del emprendimiento, con experiencia hasta de 3 o más años, dos de estos emprendimientos iniciaron su actividad hace 6 meses en la producción de sus artículos, se encuentran en proceso de perfeccionamiento de su idea de negocio, se presenta así este grupo como un potencial para la aplicación del modelo de negocio diseñado en este estudio. En cuanto a la vinculación al proyecto manifestaron: el 50\% del grupo fue por iniciativa propia y el 50\% restante por invitación de otras personas, lo cual indica que el proyecto lo encontraron importante para mejorar sus actividades productivas y los niveles de maduración en sus emprendimientos. Debido a las dificultades para vincularse a un trabajo estable, han decidido aprender las manualidades y artesanías para abrir espacios de trabajo que les genere ingresos para su sostenimiento y realización de sus negocios. Todas hacen parte de la Red de Mujeres de Chapinero. El conocimiento previo de las emprendedoras, orientó el proceso de capacitación, de un conjunto de componentes o factores que fueron básicos (entorno externo, demanda, competencia) como internos (capital inicial, capacidades de las emprendedoras, producción), lo cual orientó al equipo de investigación para las sugerencias, mejoras y actividades adicionales a tener en cuenta cada emprendedora. En cuanto al modelo de negocio (permite conocer y comprometer la menor cantidad de recursos posibles, si el negocio es viable tal y 
como se ha planteado), esta conceptualización no estaba muy clara dentro de las participantes, siempre habían hablado del plan de negocio (concreta la idea en un marco temporal y geográfico, adaptado al entorno particular generalmente donde se desarrolla la cotidianidad del emprendedor), no sabían que las empresas funcionaban dentro del esquema de modelo de negocio.

Según un estudio de la multinacional Boston Consulting Group (2018, p.1) en artículo publicado en Portafolio, y mencionado en el marco teórico de esta investigación, el emprendedor es "incapaz de diferenciarse de otros negocios sociales del país que, si bien adoptan prácticas responsables, no están enfocados en generar valor social". Otras dificultades encontradas se relacionan con:

- La falta de un modelo de negocio rentable que garantice la sostenibilidad, esto implica que en ocasiones no se cuenta con un modelo de negocio estructurado.

- El empresario no tiene claridad sobre el costo y la rentabilidad de sus productos y no realiza un análisis financiero y de capacidad para evaluar la viabilidad de una inversión.

- Se recomienda que las inversiones en maquinaria y equipo deben efectuarse tras el análisis de la capacidad, la identificación de los principales cuellos de botella en el proceso productivo y el análisis del tiempo requerido para recuperar la inversión.

Las emprendedoras en la evaluación de los emprendimientos manifestaron algunas difi- cultades a tener en cuenta para la propuesta de modelo de negocios, que sirven de base para el mejoramiento de los emprendimientos de manera individual. Se presentan a continuación los principales hallazgos:

- Falta de recursos económicos el 30 \% de emprendedoras.

Cada una de las dificultades señaladas en el presente párrafo, tiene un puntaje del $14 \%$, considerando así, igual de importancia a cada una de las variables anunciadas.

- Las dificultades de publicitar el negocio a través de las redes sociales.

- La realización del trabajo de manera individual.

- Carecen de estrategias en ventas y por lo tanto la estrategia para la retención de clientes

- Los trámites que se deben realizar con el estado son muy engorrosos.

El modelo de negocio diseñado, recoge los principales factores a considerar en cualquier emprendimiento, y que complementan el modelo CANVAS, al considerar el entorno como un componente fundamental de partida, para considerar los demás factores que constituyen la infraestructura del negocio.

La investigación fue importante debido a que facilitó el diseño de un modelo de negocio para grupos sociales, en condiciones de fragilidad por carecer de recursos que les sirva de apalancamiento a la idea de negocio, 
sin embargo, se enfatiza en la innovación que debe ser un elemento de primer orden para el emprendedor y de su idea de negocio, ya que debe transcender la puesta en marcha, el crecimiento y la consolidación del mismo.

En este modelo resalta la importancia del talento humano, los procesos de capacitación de los emprendedores, que son nulos en emprendimientos unipersonales, en la micro y pequeña empresa, por lo que se requiere por parte de los emprendedores contemplar las bondades del Servicio Nacional de Aprendizaje (SENA).

De igual manera, la Universidad es un actor muy importante en este proceso; desde la Responsabilidad Social Universitaria y proyectos de investigación, al realizar alianzas de cooperación estratégicas con los empresarios de las regiones y localidades, con el fin de construir de manera participativa, investigaciones aplicadas lo que fortalece las alianzas entre universidad y empresa como compromiso de proyección social.

Así mismo el modelo de negocio diseñado, será incluido dentro del currículo en aquellos espacios académicos que se relacionan con el emprendimiento, la innovación, creatividad, organización de negocios, de tal forma, que sea un espacio práctico para mejorar cada día el desempeño de nuestros estudiantes emprendedores y la cualificación de los docentes que intervienen en estos procesos de generar empresas para beneficio de la comunidad académica en los programas de la Facultad de Ciencias y Tecnologías y de la sociedad en general.

\section{Referencias}

Albornoz, M. (2009). Indicadores de innovación: las dificultades de un concepto en evolución. Revista Iberoamericana de Ciencia, Tecnología y Sociedad, 5(13), 9-25. Recuperado de: http:// www.redalyc.org/articulo.oa?id=92415269002

Alcaraz Rodríguez, R. (2011). El emprendedor de éxito. Cuarta edición. México D.F.: Mc Graw Hill.

Bernal, C. A. (2006). Metodología de la investigación. Para administración, economía, humanidades y ciencias sociales. Segunda edición. México: Pearson Educación.

Localidad de Chapinero, Mi ciudad, Recuperado de: https://bogota.gov.co/mi-ciudad/ localidades/ chapinero

Ferreira-Herrera, D. C. (2015). El modelo Canvas en la formulación de proyectos. Cooperativismo y Desarrollo, 23(107). DOI: http://dx.doi. org/10.16925/co.v23i107.1252.

Gerencie.com (2018). Emprendimiento. Revista de economía y finanzas, 28. Recuperado de : https://www.gerencie.com/emprendimiento. html

Global Entrepreneurship Monitor, GEM ( 2013). Informe Global. Fifteen years of assessing entrepreneurship across the globe.

Gómez, M. F. (2019). Conferencia Big data e inteligencia, artificial. Aplicaciones reales a los negocios y una reflexión sobre humanización. 
Centro de investigación DUAD, Universidad Santo Tomás, Bogotá D,C. Colombia.

Haro Pastor, G. (sf). Canvas de emprendimiento social. Emprendedor social.org Recuperado de: https://emprendedorsocial.org/canvas-de-emprendimiento-social/\#comments

Hernández Sampieri, R., Fernández Collado, C. \& Baptista Lucio, P. (2006). Metodología de la investigación. Cuarta edición. México D.F.: McGraw-Hill.

Lozano Rodríguez, C. G. \& Restrepo de Peña, B. R. (2019). Construcción del modelo de negocio para emprendedores. Informe final de investigación. Universidad Santo Tomas DUADPrograma de Administración. Bogotá, Colombia.

Lozano Tora, Ú. M. (2008). Ficha básica. Instituto Distrital de Cultura y Turismo. Localidad Chapinero, Bogotá D.,C. recuperado de: https://www.culturarecreacionydeporte.gov. co/observatorio/documentos/localidades/ chapinero.pdf

Secretaria Distrital de Planeación (SDP). (2017). Monografía 2017, Diagnóstico de los principales aspectos territoriales, de infraestructura, demográficos y socioeconómicos. Localidad No.2 Chapinero. Alcaldía Mayor de Bogotá D., C. Recuperado de: http://www.sdp.gov. co/gestion-estudios-estrategicos/informacion-cartografia-y-estadistica/repositorio-estadistico/monografia-localidad-de-chapinero- $2017 \% 5 \mathrm{D}$

Laloux, F. (2017). El futuro de las organizaciones es TEAL, del libro Reinventar las organizaciones. Revista Quaurea, 1. Recuperado de: http://www.qaurea.es/wp-content/ uploads/2017/01/Laloux-las-Organizaciones-Teal.pdf

Morris, M., Schindehutte, M. \& Allen, J. (2005). El modelo de negocio del emprendedor: hacia una perspectiva unificada. Journal of Business Research, 58(6),726-735. DOI: https://doi. org/10.1016/j.jbusres.2003.11.001.

OECD/Europlan Communities (2005). Manual de Oslo. Guía para la recogida e interpretación de datos, sobre innovación. Tercera edición, Editor y publicación en Lengua Española, grupo Tragsa.

Portafolio. Sección de emprendimiento (11/16/2018). Estas son las principales dificultades de los emprendimientos sociales. Recuperado de: https://www. portafolio.co/negocios/emprendimiento/estas-son-las-principales-dificultades-de-los-emprendedores-sociales-524494

Pearson Emprendimiento. (2012). Innovación. Revista internacional en emprendimiento y gestión, 8, (4), 1-17.

Romero, D. (2018). Alteraciones en la capacidad de apropiación de los beneficios de la innovación por la presencia de activos o bienes complementarios y cambios en el paradigma tecnológico. Revista CITAS, 4(1), 21-25. Recuperado de: https://revistas.usantotomas.edu. co/index.php/citas/article/view/5303

Romero, D. \&, Pinzón, F. A. (2017). Innovación, un acercamiento a su concepto, alcance, elementos y capacidades que la generan. Revista CITAS, 3(1), 67-71. 
Vainrub, R. (2009). Una guía para emprendedores. Convertir un sueño en realidad. Colección libros de texto. Quinta edición. México: Ediciones IESA.

Varela V., R. (2014). Innovación empresarial. Arte y ciencia en la creación de empresas. Cuarta edición, Bogotá: Editorial Delfín. Pearson educación de Colombia.

Vial, V. (2016). Business Model Canvas for Social Enterprises. Sains Humanika, 8(1-2). Recuperado de: https://sainshumanika.utm.my/index.php/sainshumanika/article/view/825

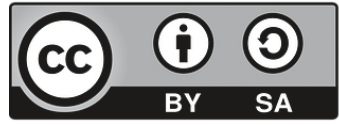

